\title{
In vitro evaluation of the root canal cleaning ability of plant extracts and their antimicrobial action
}

\author{
Edja Maria Melo de Brito Costa ${ }^{(a)}$ \\ Augusto Pierry de Araújo \\ Evangelista $^{(\mathrm{b})}$ \\ Ana Cláudia Dantas de \\ Medeiros $^{(a)}$ \\ Fábio Roberto Dametto ${ }^{(\mathrm{c})}$ \\ Rejane Andrade de Carvalho ${ }^{(c)}$
}

\footnotetext{
(a) Master's Degree Program in Dentistry, Paraiba State University, Campina Grande, PB, Brazil.
}

(b) Scientific Initiation Program, Paraiba State University, Campina Grande, PB, Brazil.

${ }^{(c)}$ Master's Degree Program in Dentistry, Potiguar University, Natal, RN, Brazil.

Declaration of Interests: The authors certify that they have no commercial or associative interest that represents a conflict of interest in connection with the manuscript.

Corresponding author:

Edja Maria Melo de Brito Costa

E-mail: edjacosta@gmail.com

Received for publication on Nov 25, 2011 Accepted for publication on Mar 07, 2012
Abstract: This in vitro study evaluated both the antimicrobial activity and the root canal cleaning ability of plant extracts used in irrigation solutions. The antimicrobial activities of the aroeira-da-praia (Schinus terebintifolius Raddi) and the quixabeira (Syderoxylum obtusifolium Roem \& Schult) hydroalcoholic extracts, of $2.5 \%$ sodium hypochlorite $(\mathrm{NaOCl})$ and of $0.12 \%$ chlorhexidine (positive control) against Enterococcus faecalis were tested with the agar well diffusion method. The level of root canal cleanliness was examined by scanning electron microscopy (SEM). Twenty one single-rooted human teeth were divided into three groups according to the irrigation solution applied: 1) $50 \%$ aroeira-da-praia; 2) 50\% quixabeira and 3) a combination of $2.5 \%$ sodium hypochlorite $+17 \%$ EDTA. All solutions tested demonstrated antimicrobial activity against Enterococcus faecalis. The SEM analysis revealed that higher and lower degrees of surface cleaning were observed, in the three groups, respectively for the coronal and apical thirds, in that quixabeira showed the greatest efficiency in removing the smear layer in the apical third. All the agents tested presented antimicrobial activity against E. faecalis. None, however, was able to completely remove the smear layer of the dentinal surface in the different thirds of the root canal. The results suggest that the analyzed plant extracts may represent a new therapeutic option in the list of alternative agents available for endodontic treatment.

Descriptors: Root Canal Irrigants; Plant Extracts; Enterococcus faecalis.

\section{Introduction}

A predominant trend in modern dentistry has been to search for biocompatible agents, especially those to be used in direct contact with tissues. ${ }^{1}$ In this context, phytotherapy has evolved as a science, and there has been growing interest in evaluating plant extracts with a potential therapeutic application in dentistry.

Cleaning of both the root canal and the dentinal tubule system, as well as proper filling of the canal, are essential procedures for the success of root canal treatment. Even when treatment is adequate, failure may occur owing to the presence of potentially pathogenic residual bacteria in sites within the canal. ${ }^{2,3}$ Thus, disinfection and shaping of the canal with a combination of chemical agents and endodontic instruments play an important role in the success of endodontic therapy. ${ }^{4}$

A number of agents have been used as auxiliary irrigation solutions for the biomechanical preparation of root canals, including ethylenediaminetet- 
raacetic acid (EDTA), sodium hypochlorite, chlorhexidine and others. ${ }^{4}$ Of these, sodium hypochlorite is currently the most widely used. Nevertheless, cytotoxic and genotoxic effects on human peripheral lymphocytes have been observed in connection with its application. ${ }^{5}$ Moreover, it has been shown that a combination of $1 \%$ $\mathrm{NaOCl}+2 \%$ chlorhexidine results in the formation of flocculate precipitates that function as a chemical smear layer, reducing dentinal permeability in the apical third.

In recent years there has been a greater interest in medicinal plants and phytotherapy because of their therapeutic and profit potential. This is particularly true on the part of the pharmaceutical industry, which continuously searches for new products that have less adverse effects. ${ }^{6-10}$

Schinus terebintifolius Raddi extract has been used as an anti-inflammatory and antimicrobial agent, and studies have demonstrated that acute and sub-acute administrations do not produce toxic effects on Wistar rats. Only a few studies have investigated the therapeutic potential of Syderoxylum obtusifolium Roem \& Schult, which has been used as an alternative medicine in the northeast of Brazil for the treatment of oral infections. ${ }^{11}$

The aim of this study was to evaluate the antimicrobial activity of aroeira-da-praia and quixabeira against Enterococcus faecalis, as well as their root canal cleaning potential in irrigation solutions.

\section{Methodology}

Obtaining the plant extracts

Schinus terebintifolius Raddi (aroeira-da-praia) and Syderoxylum obtusifolium Roem \& Schult (quixabeira) were collected in the shore region of the state of Rio Grande do Norte, Northeastern Brazil. Their extracts were obtained via percolation by immersing the desiccated plants into a $70 \%$ hydroalcoholic solution for $72 \mathrm{~h}$. This was followed by filtration and final volume adjustment of the extracts, which were then stored under room temperature in amber-colored jars.

\section{Antimicrobial activity}

The antimicrobial activity of aroeira-da-praia and quixabeira hydroalcoholic extracts against Enterococcus faecalis (ATCC 29212) was evaluated at the concentrations of $100 \%, 50 \%, 25 \%, 12.5 \%$ and $6.25 \%$. Solu- tions containing $2.5 \%$ sodium hypochlorite and $0.12 \%$ chlorhexidine were also tested. The testing described above was performed using an agar well diffusion assay. Twenty-four-hour bacterial suspensions were prepared to a 0.5 Mac Farland standard and seeded onto Petri plates containing $25 \mathrm{~mL}$ of Mueller Hinton agar. Six wells $6 \mathrm{~mm}$ in diameter were created in each plate, and filled with $50 \mu \mathrm{L}$ of the test solution. Bacterial growth inhibition halos were measured after $48 \mathrm{~h}$ at $37^{\circ} \mathrm{C}$ with a digital pachymeter. The assays were performed in triplicate. The means and standard deviations of inhibition halo measurements were calculated and the data was subjected to analysis of variance (ANOVA).

\section{Chemical-mechanical preparation}

Twenty one human single-rooted teeth were divided into three groups according to the irrigation solution used:

1. $50 \%$ aroeira-da-praia;

2. $50 \%$ quixabeira and

3. a combination of $2.5 \%$ sodium hypochlorite $+17 \%$ EDTA.

Teeth crowns were separated from the roots using a cylindrical diamond bur mounted on a high-speed turbine and under adequate refrigeration. Chemicalmechanical preparation was performed using a standard step-back technique. The study protocol was approved by the local Research Ethics Committee.

After applying each instrument, $3 \mathrm{~mL}$ of either a $50 \%$ aroeira-da-praia or a $50 \%$ quixabeira solution were used for irrigation in the experimental groups. In the control group, irrigation was performed initially with $2.5 \%$ sodium hypochlorite followed by $17 \%$ EDTA and then $3 \%$ saline solution. The teeth were maintained in $10 \%$ formalin until the root surface was analyzed using scanning electron microscopy.

\section{Scanning electron microscopy (SEM)}

The roots were cleaved longitudinally and their apical, middle and coronal thirds were examined by SEM (JEOL - JSM T330A, Tokyo, Japan). The roots were immersed in $2.5 \%$ glutaraldehyde in $0.1 \mathrm{M}$ sodium cacodylate buffer at $4{ }^{\circ} \mathrm{C}$ and $\mathrm{pH} 7.4$ for $12 \mathrm{~h}$. The same specimens were washed with $0.2 \mathrm{M}$ sodium cacodylate buffer, $\mathrm{pH} 7.4$ for $1 \mathrm{~h}$, and subsequently rinsed with dis- 
tilled water for $1 \mathrm{~min}$. This process was repeated three times. They were then dehydrated in increasing concentrations of ethanol:

- 20 min in $25 \%$ ethanol,

- $20 \mathrm{~min}$ in $50 \%$ ethanol,

- $20 \mathrm{~min}$ in $75 \%$ ethanol,

- $30 \mathrm{~min}$ in $95 \%$ ethanol and

- $1 \mathrm{~h}$ in $100 \%$ ethanol.

After dehydration, the specimens were stored overnight in an incubator at $37^{\circ} \mathrm{C}$ for drying. The specimens were metalized with a gold-palladium alloy. Photomicrographs of the apical, middle and coronal thirds of each specimen were then obtained. The images of the apical third observed in the photomicrographs were taken of a region approximately $3 \mathrm{~mm}$ from the root canal terminus, and those of the middle and coronal thirds were taken in an area approximately $6 \mathrm{~mm}$ and $9 \mathrm{~mm}$ short of the terminus, respectively. ${ }^{12}$

Analysis of the photomicrographs was based on the following scoring system, previously described: ${ }^{13}$

- 0 - absence of smear layer and presence of dentinal tubules free of residues;

- 1 - presence of smear layer or smear plugs in dentinal tubules;

- 2 - presence of smear layer and tubules free of residues in dentinal surface areas;

- 3 - presence of smear layer and tubules without clear delimitation on dentinal surface areas;

- 4 - Abundant smear layer on the dentinal surface.

\section{Results}

The two plant extracts studied presented antimicrobial activity against E. faecalis. Aroeira-da-praia demonstrated antimicrobial activity at all concentrations tested, with statistically significant differences compared to quixabeira ( $t$ test, $\mathrm{p}<0.05$ ), the latter yielding growth inhibition halos only at the concentrations of $100 \%(12.61 \mathrm{~mm})$ and $50 \%(10.20 \mathrm{~mm})$. The mean growth inhibition halos for aroeira-da-praia at the different concentrations tested $(100 \%-6.25 \%)$ were $18.91 \mathrm{~mm}, 16.32 \mathrm{~mm}, 13.93 \mathrm{~mm}, 13.08 \mathrm{~mm}$ and $11.41 \mathrm{~mm}$. The $0.12 \%$ chlorhexidine and $100 \%$ aroeirada-praia solutions induced greater mean growth inhibition halos (24 $\mathrm{mm}$ and $18.91 \mathrm{~mm}$, respectively) than the $2.5 \%$ sodium hypochlorite solution $(17.07 \mathrm{~mm})$, with a statistically significant difference $(\mathrm{p}<0.05)$. The $0.12 \%$ chlorhexidine solution produced greater bacterial growth inhibition halos than all the other solutions tested $(\mathrm{p}<0.05)$.

The data relative to the ability of the solutions to clean the root canal dentinal surface were subjected to non-parametric Kruskal-Wallis analysis. The presence of a smear layer on the dentinal surface and inside the dentinal tubules was observed in all photomicrographs examined. The images showed an irregular amorphous smear layer. There were no statistically significant differences regarding smear layer removal when the apical, middle and coronal thirds of the teeth irrigated with quixabeira extract were compared $(p=0.272)$. In the aroeira-da-praia group, the coronal third was the area in which the lowest accumulation of the smear layer on the dentinal surface was observed. In this group, there were statistically significant differences between the middle and coronal thirds $(\mathrm{p}=0.035)$, as well as between the coronal and apical thirds. There were no significant differences between the middle and apical thirds $(p=0.714)$. In the sodium hypochlorite + EDTA control group there was greater smear layer accumulation at the apical third, with a statistically significant difference when compared to the coronal $(p=0.017)$ and the middle $(p=0.009)$ thirds. There were no significant differences between the coronal and the middle thirds $(p=0.846)$. A comparison of smear layer accumulation in the root thirds of the different groups revealed statistically significant differences in the apical third, with the samples from the quixabeira and sodium hypochlorite groups showing respectively less and greater smear layer accumulation on the dentinal surface, as seen in Table 1, Figures 1 through 3.

\section{Discussion}

There has been growing interest in the use of medicinal plants for therapeutic application. Accordingly, a greater number of studies have been carried out with different plant species. Their possible activity as antimicrobial agents has been of particular interest. In the present study, it was shown that hydroalcoholic extracts of aroeira-da-praia and quixabeira display antimicrobial activity against E. faecalis. This bacterium has been related to recurrent endodontic infections, even after re-treatment. ${ }^{14,15}$ Aroeira-da-praia has been the 


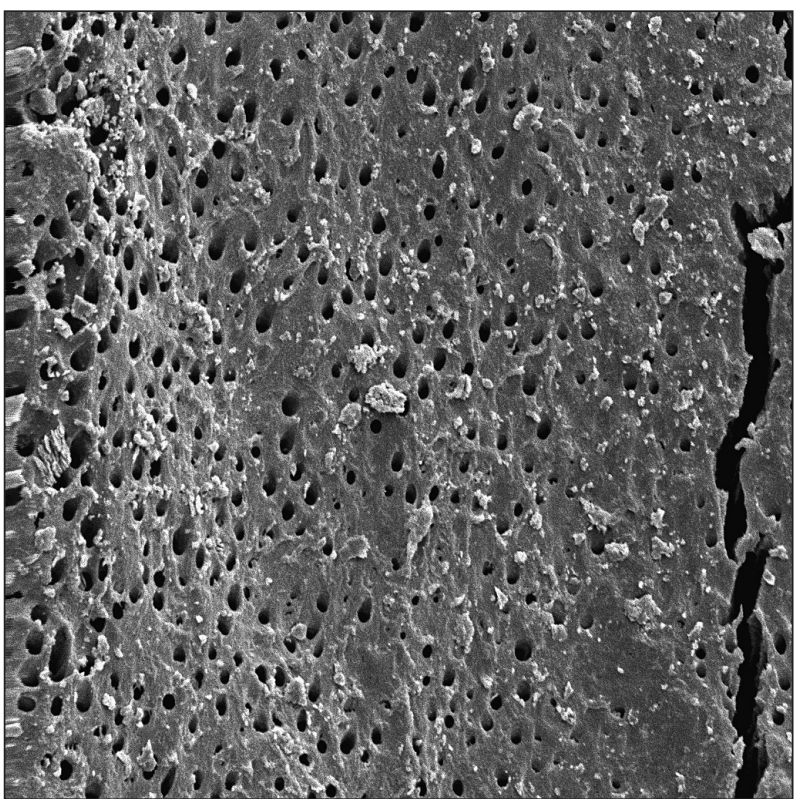

Figure 1 - Representative photomicrograph of the dentinal surface of the apical third in the quixabeira group. Numerous dentinal tubules are observed $(700 \times)$.

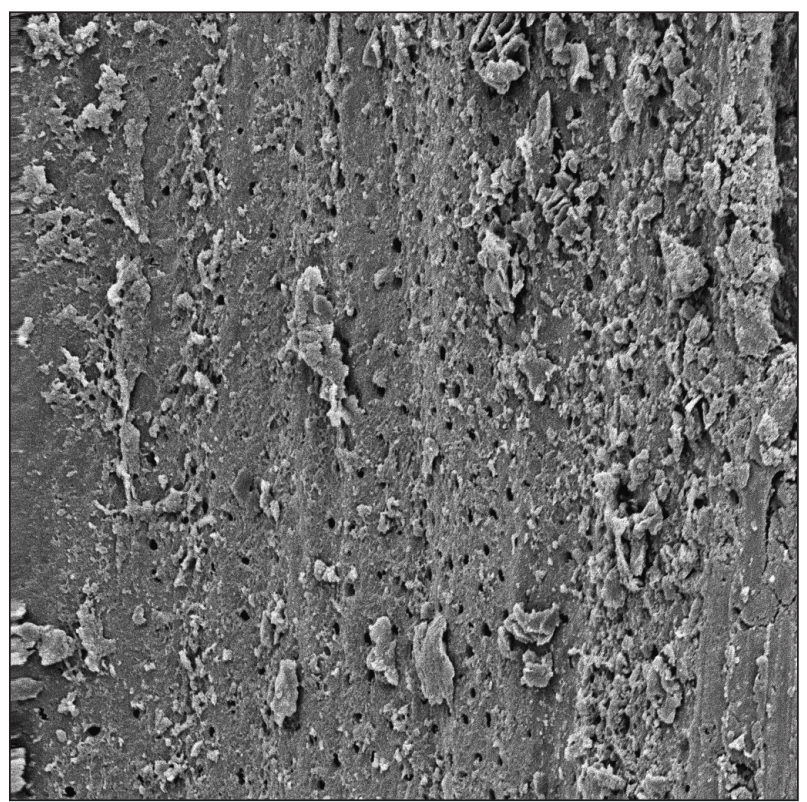

Figure 2 - Representative photomicrograph of the dentinal surface of the apical third in the aroeira-da-praia group, where dentinal tubules and smear layer are observed $(700 \times)$.

Table 1 - Score distribution with regard to smear layer removal in each group.

\begin{tabular}{c|c|c|c|c|c|c}
\hline \multirow{2}{*}{} & \multicolumn{2}{|c|}{ Aroeira } & \multicolumn{2}{c|}{ Quixabeira } & \multicolumn{2}{c}{ NaOCl + EDTA } \\
\cline { 2 - 7 } & Scores & Teeth (n) & Scores & Teeth (n) & Scores & Teeth (n) \\
\hline \multirow{4}{*}{$\begin{array}{c}\text { Coronal } \\
\text { third }\end{array}$} & 1 & - & 1 & 1 & 1 & 1 \\
\cline { 2 - 7 } & 2 & 4 & 2 & 2 & 2 & 2 \\
\cline { 2 - 7 } & 4 & 3 & 3 & 4 & 3 & 2 \\
\hline \multirow{4}{*}{$\begin{array}{c}\text { Middle } \\
\text { third }\end{array}$} & 2 & - & 4 & - & 4 & 2 \\
\cline { 2 - 7 } & 3 & - & 1 & - & 1 & - \\
\cline { 2 - 7 } & 4 & 2 & 4 & 3 & 2 & 3 \\
\hline \multirow{4}{*}{$\begin{array}{c}\text { Apical } \\
\text { third }\end{array}$} & 2 & - & 1 & - & 4 & - \\
\cline { 2 - 7 } & 3 & - & 2 & 1 & 2 & - \\
\cline { 2 - 7 } & 4 & 3 & 4 & 1 & 4 & 7 \\
\hline
\end{tabular}

object of investigation in a number of studies that have shown that this species displays antimicrobial activity against a range of microorganisms of the oral cavity. ${ }^{6,16}$ In contrast, quixabeira has not been as extensively investigated. Martinez Guerra et al. ${ }^{6}$ evaluated the activity of aroeira-da-praia extract at different concentrations and observed antimicrobial activity against Gram+ and Gram- bacteria, as well as against Candida fungi, at all concentrations tested. Similar results were also seen in the study of Martinez et al., ${ }^{16}$ where aroeira-da-praia was evaluated at concentrations of $100 \%$ and $50 \%$. In that study, however, no antimicrobial activity against Gram+ and Gram- bacteria was found at the $10 \%$ concentration. In the present study, aroeira-da-praia demonstrated antimicrobial activity at all concentrations analyzed (100\% through 6.25\%). 


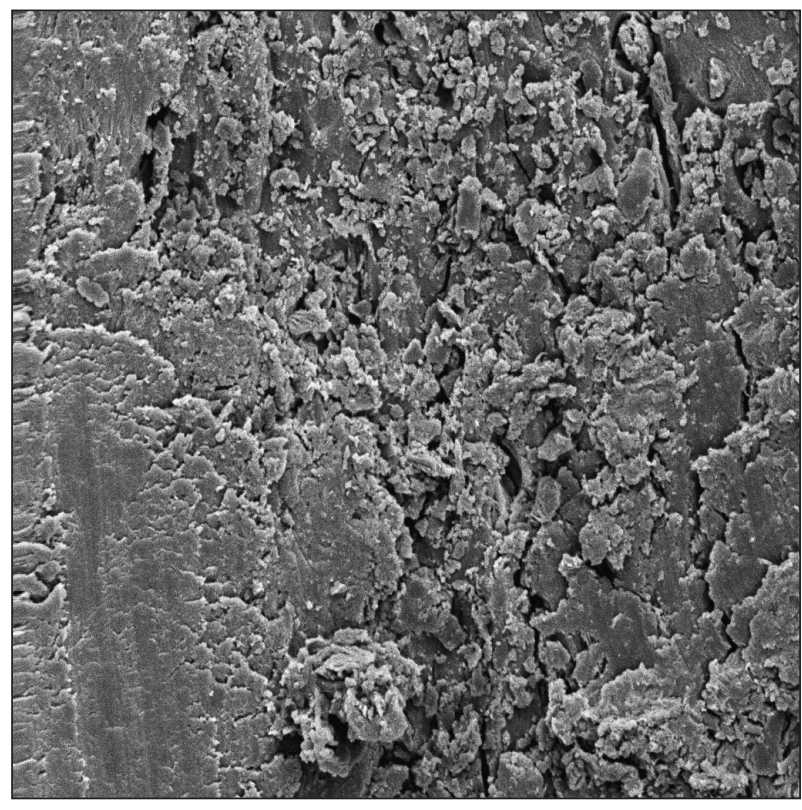

Figure 3 - Representative photomicrograph of the dentinal surface of the apical third in the $2.5 \%$ sodium hypochlorite $+17 \%$ EDTA group. An extensive area of smear layer area is observed $(700 \times)$.

A number of agents have been used in endodontic therapy as auxiliary chemical solutions during chemical-mechanical preparation. Among these, sodium hypochlorite ${ }^{14,15,17}$ and chlorhexidine ${ }^{18-20}$ have widespread use. This can probably be attributed to their antimicrobial action. ${ }^{10,19,21-23}$ Nevertheless, although chlorhexidine has been shown to have adequate antimicrobial activity, it does not dissolve residual pulp tissue. ${ }^{18,24}$

Studies have been performed associating sodium hypochlorite with other agents, especially EDTA. This combination has proved to remove debris, smear layer and smear plugs more efficiently than sodium hypochlorite alone..$^{14,15,17}$ In the present study, the use of sodium hypochlorite with EDTA did not result in superior cleaning of the root canals, when compared to the two plant extracts analyzed, and accumulation of the smear layer, mainly in the apical third, was observed in all specimens examined. Greater smear layer accumulation in the apical third has also been reported by others. ${ }^{25}$

A greater accumulation of the smear layer was observed in the apical third compared to the coronal and middle thirds, in all groups studied here. These findings may be explained by both an instrumentation-associated residue impaction and the small diameter of the region, which hinders the action of irrigation solu- tions at the instrument/dentinal surface interface of the root canal. In contrast, the coronal and middle thirds presented less smear layer accumulation in comparison with the apical third. This may be explained by the greater influx of the irrigation solutions, as well as the closer contact of the chemical agent with the root canal surface. $^{13}$

A comparison of the three solutions used in this study shows that the quixabeira solution presented the best results in terms of root surface cleaning, especially in the apical third. This may have resulted from the tonic and astringent properties of the solution. ${ }^{26}$ Conversely, the solution presenting the worst results in the apical third was the sodium hypochlorite and EDTA combination, that did not prevent abundant dentinal surface smear layer accumulation in all the teeth evaluated.

The effectiveness of the association of EDTA and sodium hypochlorite in removing the smear layer formed during endodontic instrumentation has been proven by countless authors. ${ }^{27-29}$ EDTA solutions at concentrations ranging from $15 \%$ to $17 \%$ act on the non-organic contents of the smear layer, promoting decalcification of peri- and intertubular dentin, exposing collagen without dissolving organic matter. ${ }^{28}$ On the other hand, when EDTA is associated to sodium hypochlorite, the action of the resulting solution extends to the rest of the pulp tissues $^{28,29}$ and presents antimicrobial properties..$^{30}$

The results of this study suggest that the plant extracts evaluated may represent new therapeutic options in the armamentarium of antimicrobial agents for use in endodontics. However, additional research is necessary to further substantiate their efficacy and clinical application, especially as auxiliary agents in the chemicalmechanical preparation of root canals.

\section{Conclusion}

All the agents tested for root canal cleansing presented antimicrobial activity against E. faecalis. None, however, was able to completely remove the smear layer of the dentinal surface in the different thirds of the root canal.

\section{Acknowledgments}

The authors are grateful to the National Council for Scientific and Technological Development (CNPq) for its financial support. We are also grateful to the Scien- 
tific Initiation Program of the Paraiba State University, Campina Grande, PB, Brazil, for granting a research scholarship to author A.P.A. Evangelista.

\section{References}

1. Estrela C, Holland R. Calcium hydroxide: study basic on scientific evidences. J Appl Oral Sci. 2003;11(4):269-82.

2. Nair PN, Sjögren U, Krey G, Kahnberg KE, Sundqvist G.I ntraradicular bacteria and fungi in root-filled, asymptomatic human teeth with therapy-resistant periapical lesions: a long-term light and electron microscopic follow-up study. J Endod. 1990 Dec;16(12):580-8.

3. Siqueira Jr JF. Aetiology of root canal treatment failure: why welltreated teeth can fail. Int Endod J. 2001 Jan;34(1):1-10.

8. Lima MR, Souza Luna J, Santos AF, Andrade MC, Sant'Ana AE, Genet JP, et al. Anti-bacterial activity of some Brazilian medicinal plants. J Ethnopharmacol. 2006 Apr;105(1-2):137-47.

9. Medeiros KCP, Monteiro JC, Diniz MFFM, Medeiros IA, Silva BA, Piuvezam MR. Effect of the activity of the Brazilian polyherbal formulation: Eucalyptus globulus Labill, Peltodon radicans Pohl and Schinus terebinthifolius Radd in inflammatory models. Rev Bras Farmacogn. 2007 Jan-Mar;17(1): 23-8.

10. Hendry ER, Worthington T, Conway BR, Lambert PA. Antimicrobial efficacy of eucalyptus oil and 1,8-cineole alone and in combination with chlorhexidine digluconate against microorganisms grown in planktonic and biofilm cultures. J Antimicrob Chemother. 2009 Dec;64(6):1219-25.

11. Santos EB, Dantas GS, Santos HB, Diniz MFFM, Sampaio FC. Etnobotanical studies of medicinal plants for oral conditions in the municipality of João Pessoa, Brazil. Rev Bras Farmacogn. 2009 Jan-Mar;19(1b):321-

12. Roselino Ribeiro AL, Noriega JR, Dametto FR, Vaz LG. Compressive fatigue in titanium dental implants submitted to fluride íons action. J Appl Oral Sci. 2007 Jul-Aug;15(4):299-304.

13. Gesteira MFM, Silva SJA, Araújo RPC, Lenzi H, Rocha MCBS. The effect of EDTA in cervical, basal and apical thirds on the removal of the smear layer. J Med Biol Sci. 2003 Jul-Dec;2(2):208-18.

14. Soares JA, Roque de Carvalho MA, Cunha Santos SM, Castro Mendonça RM, Ribeiro-Sobrinho AP, Brito-Júnior M, et al. Effectiveness of chemomechanical preparation with alternating use of sodium hypochlorite and EDTA in eliminating intracanal Enterococcus faecalis biofilm. J Endod. 2010 May;36(5):894-8.

15. Ozdemir HO, Buzoglu HD, Calt S, Stabholz A, Steinberg D. Effect of ethylenediaminetetraacetic acid and sodium hypochlorite irrigation on Enterococcus faecalis biofilm colonization in young and old human root canal dentin: in vitro study. J Endod. 2010 May;36(5):842-6.

16. Martínez MJ, Betancourt J, Alonso-González N, Jauregui A. Screening of some Cuban medicinal plants for antimicrobial activity. J. Ethnopharmacol. 1996 Jul;52(3):171-4.
4. Medici MC, Froner IC. A scanning electron microscopic evaluation of different root canal irrigation regimes. Braz Oral Res. 2006 JulAug; 20(3):235-40.

5. Gül S, Savsar A, Tayfa Z. Cytotoxic and genotoxic effects of sodium hypochlorite on human peripheral lymphocytes in vitro. Cytotechnology. 2009;59(2):113-9. doi: 10.1007/s10616-009-92014.

6. Martínez Guerra MJ, López Barreiro M, Morejón Rodríguez Z, Rubalcaba Y. Actividad antimicrobiana de un extracto fluido al 80 porciento de Schinus terebinthifolius Raddi (copal). Rev Cubana Plant Med. 2000 Abr;5(1):23-5.

7. Brandão MGL, Cosenza GP, Moreira RA, Monte-Mor RLM. Medicinal plants and other botanical products from the Brazilian Official Pharmacopoeia. Rev Bras Farmacogn. 2006 JulSep;16(3):408-20.

17. Cengiz T, Aktener BO, Piskin B. Effect of dentinal tubule orientation on the removal of smear layer by root canal irrigants. A scanning electron microscopic study. Int Endod J. 1990 May;23(3):16371.

18. Ferraz CC, Gomes BP, Zaia AA, Teixeira FB, Souza-Filho FJ. In vitro assessment of the antimicrobial action and the mechanical ability of chlorhexidine gel as an endodontic irrigant. J Endod. $2001 \mathrm{Jul} ; 27(7): 452-5$.

19. Gomes BP, Ferraz CC, Vianna ME, Berber VB, Teixeira FB, Souza-Filho FJ, et al. In vitro antimicrobial activity of several concentrations of sodium hypochlorite and chlorhexidine gluconate in the elimination of Enterococcus faecalis. Int Endod J. 2001 Sep;34(6):424-8.

20. Shen Y, Stojicic S, Qian W, Olsen I, Haapasalo M. The synergistic antimicrobial effect by mechanical agitation and two chlorhexidine preparations on biofilm bacteria. J Endod. 2010 Jan;36(1):100-4.

21. Ercan E, Ozekinci T, Atakul F, Gül K. Antibacterial activity of $2 \%$ chlorhexidine gluconate and $5.25 \%$ sodium hypochlorite in infected root canal: in vivo study. J Endod. 2004 Feb;30(2):84-7.

22. Giardino L, Savoldi E, Ambu E, Rimondini R, Palezona A, Debbia EA. Antimicrobial effect of MTAD, Tetraclean, Cloreximid, and sodium hypochlorite on three common endodontic pathogens. Indian J Dent Res. 2009 Jul-Sep;20(3):391.

23. Prabhakar J, Senthilkumar M, Priya MS, Mahalakshmi K, Sehgal PK, Sukumaran VG. Evaluation of antimicrobial efficacy of herbal alternatives (Triphala and green tea polyphenols), MTAD, and 5\% sodium hypochlorite against Enterococcus faecalis biofilm formed on tooth substrate: an in vitro study. J Endod. 2010 Jan;36(1):83-6.

24. Okino LA, Siqueira EL, Santos M, Bombana AC, Figueiredo JA. Dissolution of pulp tissue by aqueous solution of chlorhexidine digluconate and chlorhexidine digluconate gel. Int Endod J. $2004 \mathrm{Jan} ; 37(1): 38-41$.

25. Akisue E, Tomita VS, Gavini G, Figueiredo JAP. Effect of the combination of sodium hypochlorite and chlorhexidine on den- 
tinal permeability and scanning electron microscopy precipitate observation. J Endod. 2010 May;36(5):847-50.

26. Silva FB, Almeida JM, Sousa SM. Natural medicaments in endodontics -- a comparative study of the anti-inflammatory action. Braz Oral Res. 2004 Apr-Jun;18(2):174-9.

27. Goldman M, Goldman LB, Cavaleri R, Bogis J, Lin PS. The efficacy of several endodontic irrigating solutions: a scanning electron microscopic study: part 2. J Endod. 1982;8(11):487-92.

28. Baumgartner JC, Mader CL. A scanning electron microscopic evaluation of four root canal irrigation regimens. J Endod. 1987;13(4):147-57.

29. Abbott PV, Heijkoop PS, Cardaci SC, Hume WR, Heithersay GS. An SEM study of the effects of different irrigation sequences and ultrasonics. Int Endod J. 1991;24(6):308-16.

30. Baumgartner JC, Cuenin PR. Efficacy of several concentrations of sodium hipochlorite for root canal irrigation. J Endod. 1992;18(12):605-12. 